\title{
Efeito da frequência de irrigação e fósforo nas características biométricas do milho
}

\author{
Effect of frequency of irrigation and phosphorus on biometric characteristics of corn \\ Efecto de la frecuencia de riego y fósforo sobre las características biométricas del maíz
}

Recebido: 06/02/2021 | Revisado: 12/02/2021 | Aceito: 16/02/2021 | Publicado: 23/02/2021

\author{
Reginaldo Miranda de Oliveira \\ ORCID: https://orcid.org/0000-0002-1880-0730 \\ Universidade Federal de Viçosa, Brasil \\ E-mail: reginaldo.miranda@ufv.br \\ Rubens Alves de Oliveira \\ ORCID: https://orcid.org/0000-0003-2557-592X \\ Universidade Federal de Viçosa, Brasil \\ E-mail: rubens@ufv.br \\ Ednaldo Miranda de Oliveira \\ ORCID: https://orcid.org/0000-0002-1182-7623 \\ Instituto Federal do Espírito Santo, Brasil \\ E-mail: ednaldo.oliveira@ifes.edu.br \\ Margareth Evangelista Botelho \\ ORCID: https://orcid.org/0000-0001-8746-2272 \\ Universidade Federal de Viçosa, Brasil \\ E-mail: margareth.botelho@ufv.br \\ Job Teixeira de Oliveira \\ ORCID: https://orcid.org/0000-0001-9046-0382 \\ Universidade Federal do Mato Grosso do Sul, Brasil \\ E-mail: job.oliveira@hotmail.com
}

\begin{abstract}
Resumo
O aproveitamento hídrico pela cultura do milho aparentemente está intimamente relacionada aos níveis de fósforo disponível no solo. O objetivo deste trabalho foi avaliar o efeito da frequência de irrigação combinado a diferentes doses de adubação fosfatada nas características biométricas da cultura do milho sob duas densidades de plantio. O experimento foi instalado num esquema de parcelas sub-subdivididas. Na parcela principal sete frequências de irrigação e duas populações de plantas. Nas sub-subparcelas, cinco doses de fósforo. A população de 80 mil plantas ha $^{-1}$ apresentou maior altura de plantas e de inserção de espigas, independente do turno de rega adotado e da dose de fósforo aplicada. A população de 60 mil plantas ha $^{-1}$, apresentou maior comprimento de espigas, número de grãos na fileira e massa de 1000 grãos. Doses crescentes de fósforo, afetaram as alturas de plantas e altura de inserção de espigas na população de 60 mil plantas ha ${ }^{-1}$. Já a população de 80 mil plantas ha $^{-1}$, doses crescentes de fósforo afetaram diâmetro de caule. Não foi evidenciado efeito da adubação fosfatada nas características produtivas estudadas: índice de colheita, diâmetro de espigas, comprimento de espigas, número de fileiras de grãos, número de grãos na fileira e massa de 1000 grãos.
\end{abstract}

Palavras-chave: Adubação; Fertirrigação; Irrigação mecanizada; Zea mays.

\begin{abstract}
The water use by the corn crop is apparently closely related to the levels of phosphorus available in the soil. The objective of this work was to evaluate the effect of irrigation frequency combined with different doses of phosphate fertilizer on the biometric characteristics of the corn crop under two planting densities. The experiment was installed in a scheme of subdivided plots. In the main plot, seven irrigation frequencies and two plant populations. In the subsubplots, five doses of phosphorus. The population of 80 thousand plants ha ${ }^{-1}$ showed higher plant height and ear insertion, regardless of the irrigation shift adopted and the dose of phosphorus applied. The population of 60 thousand plants ha ${ }^{-1}$, showed a greater length of ears, number of grains in the row and a mass of 1000 grains. Increasing doses of phosphorus, affected plant heights and ear insertion height in the population of 60 thousand plants $\mathrm{ha}^{-1}$. As for the population of 80 thousand plants ha ${ }^{-1}$, increasing doses of phosphorus affected stem diameter. There was no effect of phosphate fertilization on the productive characteristics studied: harvest index, ear diameter, ear length, number of grain rows, number of grains in the row and mass of 1000 grains.
\end{abstract}

Keywords: Fertilization; Fertigation; Mechanized irrigation; Zea mays. 


\begin{abstract}
Resumen
El uso de agua por el cultivo de maíz aparentemente está estrechamente relacionado con los niveles de fósforo disponible en el suelo. El objetivo de este trabajo fue evaluar el efecto de la frecuencia de riego combinada con diferentes dosis de fertilizante fosfatado sobre las características biométricas del cultivo de maíz bajo dos densidades de siembra. El experimento se instaló en un esquema de parcelas subdivididas. En la parcela principal, siete frecuencias de riego y dos poblaciones de plantas. En las sub-subparcelas, cinco dosis de fósforo. La población de 80 mil plantas ha ${ }^{-1}$ mostró mayor altura de planta e inserción de mazorcas, independientemente del turno de riego adoptado y la dosis de fósforo aplicada. La población de 60 mil plantas ha ${ }^{-1}$, mostró mayor longitud de mazorcas, número de granos en la hilera y una masa de 1000 granos. Dosis crecientes de fósforo, altura de plantas afectadas y

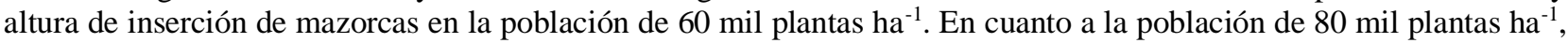
las dosis crecientes de fósforo afectaron el diámetro del tallo. No hubo efecto de la fertilización fosfatada sobre las características productivas estudiadas: índice de cosecha, diámetro de la mazorca, longitud de la mazorca, número de filas de granos, número de granos en la fila y masa de 1000 granos.
\end{abstract}

Palabras clave: Fertilización; Fertrigación; Riego mecanizado; Zea mays.

\title{
1. Introdução
}

A área de milho primeira safra, na temporada 2019/20, atingiu 4,2 milhões de hectares, 3,2\% maior que a área cultivada na safra anterior. Na segunda safra de milho, a produção deve ser 2,4\% maior que à da safra anterior, isso devido ao incremento na área cultivada em 6,7\%. O milho cultivado na terceira safra é caracterizado por apresentar um calendário produtivo semelhante ao do hemisfério norte. A produção total na safra 2019/20 é estimada em 1.539,9 mil toneladas (Conab, 2020).

Autores como Oliveira et al., 2018 e Oliveira et al., 2020a, estudaram características biométricas de culturas agrícolas e destacam a sua importância para entendimento do comportamento da planta em função do manejo implementado na cultura, seja ele hídrico ou nutricional. De acordo com Soares et al. (2017), fatores como a disponibilidade hídrica, ciclo da cultura, espaçamento, época de semeadura, boas condições nutricionais e uma população entre 30.000 e 90.000 plantas ha $^{-1}$, são essenciais para que a cultura do milho atinja seu potencial máximo de produção.

Tem sido relatada a existência de relação direta entre a demanda hídrica e teores de nutrientes no solo (Oliveira et al., 2020b). Neste sentido, o estudo da influência da frequência de irrigação e doses de fósforo, pode fornecer subsídios para escolha da melhor forma de condução da lavoura e, consequentemente, contribuir para melhorar a eficiência na absorção deste nutriente.

O objetivo deste trabalho, foi avaliar o efeito da frequência de irrigação combinado a diferentes doses de adubação fosfatada e densidades de plantio nas características biométricas da cultura do milho.

\section{Material e Métodos}

O experimento foi conduzido no ano agrícola 2017/2018, na Universidade Federal de Viçosa (UFV). A área experimental está situada a 732535.39 m E 7694979.73 m S, com altitude de 716 m. Após análise física do solo, o mesmo foi classificado como Argissolo Vermelho-Amarelo distrófico, argiloso/argiloso com relevo suave ondulado, caulinítico (PVAd) (Embrapa, 2017).

Antes de realizar o plantio, foram retiradas amostras de solo na camada de 0 a $0,20 \mathrm{~m}$ de profundidade para caracterização física e química do solo. O solo da área utilizada é composto por $58 \%$ de argila, $18 \%$ de silte e $24 \%$ de areia grossa, com densidade de $1,30 \mathrm{~g} \mathrm{~cm}^{-3}$. Utilizando o Extrator de Richards, foi determinado que a capacidade de campo e o ponto de murcha permanente do solo eram de 0,335 e $0,180 \mathrm{~g} \mathrm{~g}^{-1}$ respectivamente. A média de P disponível no solo imediatamente antes do plantio era de $27,46 \mathrm{mg} \mathrm{dm}^{-3}$. 
A quantidade de suprimento de $\mathrm{P}$ de cada tratamento foi obtida considerando-se a quantidade de fósforo já existente no solo na camada de 0 a $0,20 \mathrm{~m}$, determinada na análise de solo, acrescida da quantidade de $\mathrm{P}$ suprida via fertilizante. Os demais tratos culturais ocorreram de acordo com o recomendado para a cultura do milho na região.

$\mathrm{O}$ experimento foi instalado num esquema de parcelas sub-subdivididas, tendo nas parcelas principais o turno de rega $\left(\mathrm{TR}_{1}=1\right.$ dia; $\mathrm{TR}_{2}=2$ dias; $\mathrm{TR}_{3}=3$ dias; $\mathrm{TR}_{4}=4$ dias; $\mathrm{TR}_{5}=5$ dias; $\mathrm{TR}_{6}=6$ dias e $\mathrm{TR}_{7}=7$ dias $)$, nas subparcelas duas populações de plantas $\left(\mathrm{P}_{60}=60.000\right.$ e $\mathrm{P}_{80}=80.000$ plantas ha $\left.^{-1}\right)$ e nas sub-subparcelas as doses de fósforo $\left(\mathrm{D}_{0}=0 \mathrm{~kg} \mathrm{ha}^{-1} ; \mathrm{D}_{50}\right.$ $=50 \mathrm{~kg} \mathrm{ha}^{-1} ; \mathrm{D}_{100}=100 \mathrm{~kg} \mathrm{ha}^{-1}$ e $\mathrm{D}_{200}=200 \mathrm{~kg} \mathrm{ha}^{-1} \mathrm{de}_{2} \mathrm{O}_{5}$ ). O plantio foi feito com linhas espaçadas de $0,50 \mathrm{~m}$ e $0,33 \mathrm{~m}$ entre plantas na $\mathrm{P}_{80}$ e 0,25 m entre plantas na $\mathrm{P}_{60}$. Cada unidade experimental foi composta de 5 linhas de plantio com 5 metros, sendo a área útil da parcela igual a 7,50 $\mathrm{m}^{2}$, uma vez que as linhas de plantio das extremidades foram bordaduras.

O manejo da irrigação foi conduzido utilizando-se do programa computacional REF-ET descrita por Ahmadipour et al, (2019) para o cálculo diário da evapotranspiração de referência $\left(\mathrm{ET}_{0}\right)$, usando-se dados meteorológicos horários obtidos em uma estação meteorológica automática Davis Vantage Pro II, instalada próxima a área experimental.

O híbrido de milho utilizado no plantio foi o DKB 390 Pro-III, híbrido simples, de ciclo precoce, com arquitetura foliar semi-ereta. Altura média de plantas variando de 2,25 m a 2,45 m, a altura de inserção de espiga de 1,25 m a 1,40 m. Boa tolerância a elevadas temperaturas, ampla adaptação a diferentes tipos de solo e manejo e com finalidade de produção de grãos.

A semeadura foi realizada no dia 09/01/2017 e feita uma adubação com superfosfato triplo ( $46 \%$ de $\mathrm{P}_{2} \mathrm{O}_{5}$ ) de acordo com os tratamentos testados. A adubação com nitrogênio e potássio foram feitas em duas aplicações em cobertura, quando as plantas de milho se encontravam nos estádios fenológicos V3 e V6, apresentando três e seis folhas totalmente formadas, respectivamente. As doses foram calculadas com base no resultado da análise química do solo e nas Recomendações para o Uso de Corretivos e Fertilizantes em Minas Gerais, $5^{\mathrm{a}}$ Aproximação (Ribeiro et al., 1999). Foram aplicados $170 \mathrm{~kg} \mathrm{ha}^{-1}$ de $\mathrm{N}$ na forma de sulfato de amônia e $120 \mathrm{~kg} \mathrm{ha}^{-1} \mathrm{de} \mathrm{K}$ na forma de cloreto de potássio, igualmente divididos nas duas aplicações.

No estádio de florescimento, quatro plantas por unidade experimental foram utilizadas para a avaliação das seguintes características biométricas: altura de planta (AP) - distância entre a superfície do solo até a folha bandeira; altura de inserção de espiga (AIE) - distância entre a superfície do solo e o entrenó da base da inflorescência feminina; diâmetro de colmo (DC) - diâmetro do colmo no primeiro entrenó acima do colo da planta (medido com auxílio de um paquímetro).

Após a colheita, foram usadas quatro espigas por unidade experimental para a avaliação das seguintes características agronômicas: o diâmetro da espiga (DE) - diâmetro médio da parte central das espigas, em cm; o comprimento de espiga (CE) - comprimento médio da base à ponta da espiga, em cm; número de fileiras de grãos por espiga (NF)- número médio de fileiras de grãos; número de grãos por fileira (NGF) - número médio de grãos por fileira. Foi determinado o peso de 1000 grãos $\left(\mathrm{P}_{1000}\right)$ corrigido para o teor de umidade a $13 \%$ com uso de balança digital com precisão $0,01 \mathrm{~g}$.

Adicionalmente, na colheita, uma planta de cada unidade experimental foi cortada rente ao solo para determinação da massa seca da parte aérea das plantas de milho. Todas as partes constituintes da planta foram amostradas, o material foi seco em estufa de circulação de ar à $65^{\circ} \mathrm{C}$ até obtenção de massa constante para determinação dos teores de matéria seca. Posteriormente, foi calculada a massa seca da parte aérea e foi determinado o índice de colheita (IC) como sendo a relação entre a massa seca dos grãos e a massa seca da parte aérea das plantas de milho.

Todos os dados foram submetidos à análise de variância. Foi utilizado o teste de Tukey para a comparação das médias em função das populações e dos turnos de rega. Já para a avaliação dos efeitos da dose de adubação, foi utilizada análise de regressão. A significância dos parâmetros da regressão foi avaliada pelo teste "t". Apena equações cujos paramentos foram todos significativos foram consideradas. Em todas as análises estatísticas, adotou-se o nível de 5\% de probabilidade. 


\section{Resultados e Discussão}

Na Figura 1, estão apresentadas as variações das temperaturas máxima, mínima e média diária e da umidade relativa média diária do ar durante o período experimental.

Figura 1 - Variação das temperaturas máxima, mínima e média diária e da umidade relativa diária do ar durante o período experimental, nos estádios fenológicos I (inicial), II (vegetativo), III (florescimento) e IV (maturação).

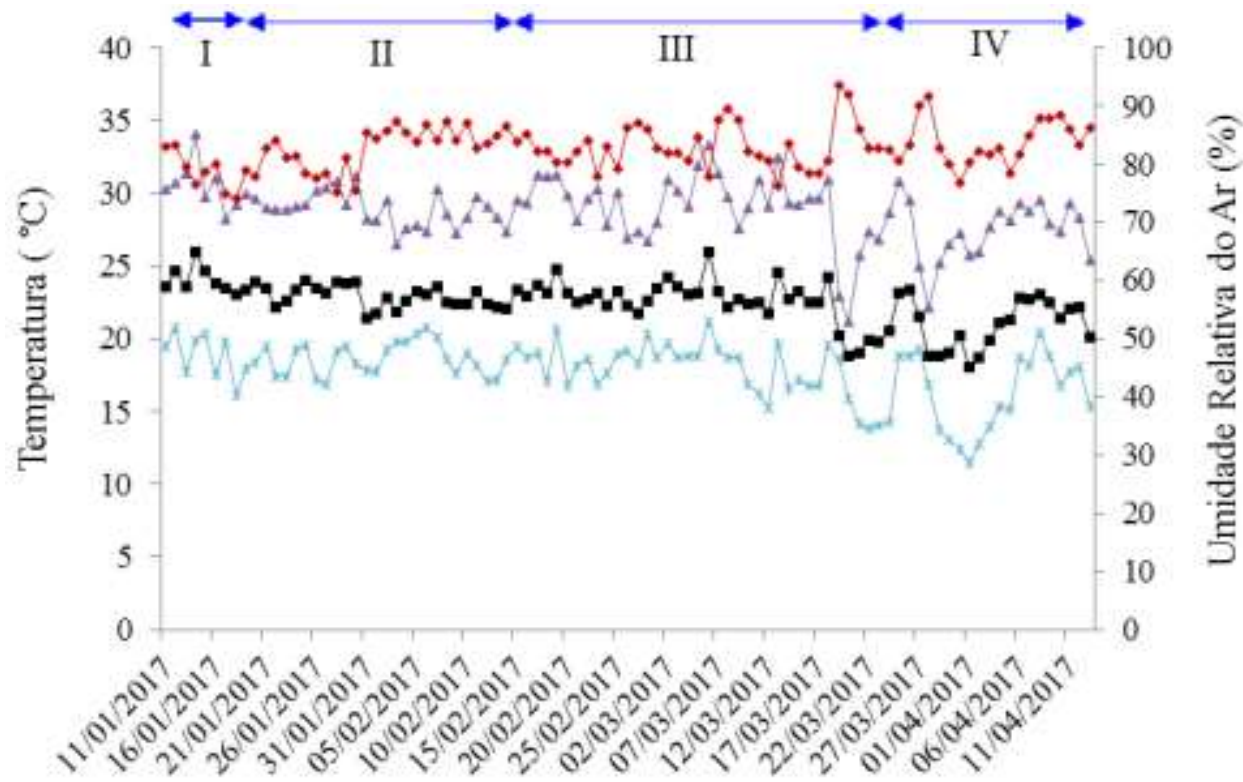

Data

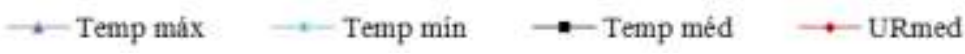

Fonte: Autores.

Temperaturas entre 25 a $30^{\circ} \mathrm{C}$ propiciam melhores condições para germinação e emergência das plântulas. Segundo Mangili (2014), temperaturas médias diárias acima de $26^{\circ} \mathrm{C}$ causam aceleração dos estádios fenológicos e temperaturas médias diárias inferiores a $15^{\circ} \mathrm{C}$ podem retardar o desenvolvimento das plantas. Portanto, para as condições deste experimento pode ser observado que ao longo dos estádios fenológicos da cultura a temperatura ficou dentro do ideal para o cultivo favorescendo bons resultados.

Apesar de terem sido verificadas ocorrências de 32 eventos de precipitação, totalizando 370,20 mm ao longo do período experimental. As precipitações apresentaram distribuição irregular durante o ciclo da cultura, não atendendo de forma adequada a demanda hídrica do milho em estádios fenológicos críticos para o desenvolvimento da planta e formação dos grãos. Sendo, portanto, justificada a importância de uso da irrigação para complementar e evitar déficits de água no solo.

Na Tabela 1, estão apresentadas as comparações de médias para a característica altura de plantas, diâmetro de colmo e altura de inserção de espigas para a cultura do milho segunda safra no ano de 2017. 
Tabela 1 - Valores médios das características biométricas para as combinações dos níveis de turno de rega, população de plantas e dose de adubação com fósforo.

\begin{tabular}{|c|c|c|c|c|c|c|c|c|}
\hline \multirow{2}{*}{ Turno de Rega } & \multicolumn{2}{|c|}{$\mathrm{D}_{0}$} & \multicolumn{2}{|c|}{$\mathrm{D}_{50}$} & \multicolumn{2}{|c|}{$\mathrm{D}_{100}$} & \multicolumn{2}{|c|}{$\mathrm{D}_{200}$} \\
\hline & $\mathrm{P}_{60}$ & $\mathrm{P}_{80}$ & $\mathrm{P}_{60}$ & $\mathrm{P}_{80}$ & $\mathrm{P}_{60}$ & $\mathrm{P}_{80}$ & $\mathrm{P}_{60}$ & $\mathrm{P}_{80}$ \\
\hline \multicolumn{9}{|c|}{ altura de plantas (AP) (m) } \\
\hline $\mathrm{TR}_{1}$ & $2,52^{\mathrm{Bb}}$ & $2,77^{\mathrm{Aa}}$ & $2,60^{\mathrm{Ab}}$ & $2,72^{\mathrm{Aa}}$ & $2,54^{\mathrm{Ab}}$ & $2,82^{\mathrm{Aa}}$ & $2,73^{\mathrm{Ab}}$ & $2,81^{\mathrm{Aa}}$ \\
\hline $\mathrm{TR}_{2}$ & $2,70^{\mathrm{Aa}}$ & $2,73^{\mathrm{Aa}}$ & $2,55^{\mathrm{Ab}}$ & $2,71^{\mathrm{Aa}}$ & $2,55^{\mathrm{Ab}}$ & $2,76^{\mathrm{Aa}}$ & $2,51^{\mathrm{Bb}}$ & $2,73^{\mathrm{Ba}}$ \\
\hline $\mathrm{TR}_{3}$ & $2,52^{\mathrm{Bb}}$ & $2,77^{\mathrm{Aa}}$ & $2,60^{\mathrm{Ab}}$ & $2,72^{\mathrm{Aa}}$ & $2,54^{\mathrm{Ab}}$ & $2,81^{\mathrm{Aa}}$ & $2,73^{\mathrm{Ab}}$ & $2,81^{\mathrm{Aa}}$ \\
\hline $\mathrm{TR}_{4}$ & $2,70^{\mathrm{Aa}}$ & $2,73^{\mathrm{Aa}}$ & $2,55^{\mathrm{Ab}}$ & $2,71^{\mathrm{Aa}}$ & $2,55^{\mathrm{Ab}}$ & $2,76^{\mathrm{Aa}}$ & $2,51^{\mathrm{Bb}}$ & $2,73^{\mathrm{Ba}}$ \\
\hline $\mathrm{TR}_{5}$ & $2,52^{\mathrm{Bb}}$ & $2,77^{\mathrm{Aa}}$ & $2,60^{\mathrm{Ab}}$ & $2,72^{\text {Аa }}$ & $2,54^{\mathrm{Ab}}$ & $2,81^{\mathrm{Aa}}$ & $2,73^{\mathrm{Ab}}$ & $2,81^{\mathrm{Aa}}$ \\
\hline $\mathrm{TR}_{6}$ & $2,70^{\mathrm{Aa}}$ & $2,72^{\mathrm{Aa}}$ & $2,55^{\mathrm{Ab}}$ & $2,71^{\mathrm{Aa}}$ & $2,56^{\mathrm{Ab}}$ & $2,76^{\mathrm{Aa}}$ & $2,50^{\mathrm{Bb}}$ & $2,74^{\mathrm{Ba}}$ \\
\hline $\mathrm{TR}_{7}$ & $2,70^{\mathrm{Aa}}$ & $2,73^{\mathrm{Aa}}$ & $2,55^{\mathrm{Ab}}$ & $2,71^{\mathrm{Aa}}$ & $2,55^{\mathrm{Ab}}$ & $2,77^{\mathrm{Aa}}$ & $2,51^{\mathrm{Bb}}$ & $2,73^{\mathrm{Ba}}$ \\
\hline \multicolumn{9}{|c|}{ diâmetro de colmo (DC) $(\mathrm{cm})$} \\
\hline $\mathrm{TR}_{1}$ & $2,46^{\mathrm{Aa}}$ & $2,54^{\mathrm{Ab}}$ & $2,21^{\mathrm{Aa}}$ & $2,35^{\mathrm{ABa}}$ & $2,48^{\mathrm{Aa}}$ & $2,33^{\mathrm{Aa}}$ & $2,39^{\text {Aa }}$ & $2,30^{\mathrm{Ba}}$ \\
\hline $\mathrm{TR}_{2}$ & $2,29^{\mathrm{ABa}}$ & $2,34^{\mathrm{ABa}}$ & $2,24^{\mathrm{Ab}}$ & $2,47^{\mathrm{Aa}}$ & $2,30^{\mathrm{ABa}}$ & $2,36^{\mathrm{Aa}}$ & $2,38^{\mathrm{Aa}}$ & $2,21^{\mathrm{Bb}}$ \\
\hline $\mathrm{TR}_{3}$ & $2,26^{\mathrm{ABb}}$ & $2,51^{\mathrm{ABCa}}$ & $2,20^{\mathrm{Ab}}$ & $2,40^{\mathrm{ABa}}$ & $2,12^{\mathrm{Bb}}$ & $2,30^{\mathrm{Aa}}$ & $2,23^{\mathrm{Ab}}$ & $2,56^{\mathrm{Aa}}$ \\
\hline $\mathrm{TR}_{4}$ & $2,27^{\mathrm{ABa}}$ & $2,26^{\mathrm{BCa}}$ & $2,34^{\mathrm{Aa}}$ & $2,22^{\mathrm{BCDa}}$ & $2,23^{\mathrm{Ba}}$ & $2,28^{\mathrm{Aa}}$ & $2,25^{\text {Аа }}$ & $2,21^{\mathrm{Ba}}$ \\
\hline $\mathrm{TR}_{5}$ & $2,39^{\mathrm{ABa}}$ & $2,29^{\mathrm{BCa}}$ & $2,42^{\mathrm{Aa}}$ & $2,36^{\mathrm{ABCa}}$ & $2,21^{\mathrm{Ba}}$ & $2,26^{\mathrm{Aa}}$ & $2,30^{\mathrm{Aa}}$ & $2,11^{\text {Ва }}$ \\
\hline TR6 & $2,29^{\mathrm{ABa}}$ & $2,24^{\mathrm{BCa}}$ & $2,32^{\text {Aa }}$ & $2,16^{\mathrm{CDa}}$ & $2,34^{\mathrm{ABa}}$ & $2,21^{\mathrm{Aa}}$ & $2,25^{\mathrm{Ab}}$ & $2,42^{\mathrm{ABa}}$ \\
\hline $\mathrm{TR}_{7}$ & $2,17^{\mathrm{Ba}}$ & $2,06^{\mathrm{Ca}}$ & $2,24^{\mathrm{Aa}}$ & $2,07^{\mathrm{Db}}$ & $2,23^{\mathrm{Ba}}$ & $2,19^{\mathrm{Aa}}$ & $2,28^{\mathrm{Aa}}$ & $2,34^{\mathrm{ABa}}$ \\
\hline \multicolumn{9}{|c|}{ altura de inserção de espigas (AIE) (m) } \\
\hline $\mathrm{TR}_{1}$ & $1,52^{\mathrm{Ab}}$ & $1,66^{\mathrm{Aa}}$ & $1,53^{\mathrm{Ab}}$ & $1,62^{\mathrm{Aa}}$ & $1,48^{\mathrm{Ab}}$ & $1,68^{\mathrm{Aa}}$ & $1,63^{\mathrm{Aa}}$ & $1,64^{\mathrm{Aa}}$ \\
\hline $\mathrm{TR}_{2}$ & $1,55^{\mathrm{Ab}}$ & $1,66^{\mathrm{Aa}}$ & $1,54^{\mathrm{Ab}}$ & $1,61^{\mathrm{Aa}}$ & $1,51^{\mathrm{Ab}}$ & $1,72^{\mathrm{Aa}}$ & $1,43^{\mathrm{Bb}}$ & $1,62^{\mathrm{Aa}}$ \\
\hline $\mathrm{TR}_{3}$ & $1,52^{\mathrm{Ab}}$ & $1,66^{\mathrm{Aa}}$ & $1,53^{\mathrm{Ab}}$ & $1,62^{\text {Aa }}$ & $1,48^{\mathrm{Ab}}$ & $1,68^{\mathrm{Aa}}$ & $1,63^{\mathrm{Aa}}$ & $1,64^{\mathrm{Aa}}$ \\
\hline $\mathrm{TR}_{4}$ & $1,55^{\mathrm{Ab}}$ & $1,66^{\mathrm{Aa}}$ & $1,54^{\mathrm{Ab}}$ & $1,61^{\mathrm{Aa}}$ & $1,51^{\mathrm{Ab}}$ & $1,72^{\mathrm{Aa}}$ & $1,43^{\mathrm{Bb}}$ & $1,62^{\mathrm{Aa}}$ \\
\hline $\mathrm{TR}_{5}$ & $1,53^{\mathrm{Ab}}$ & $1,66^{\mathrm{Aa}}$ & $1,53^{\mathrm{Ab}}$ & $1,62^{\mathrm{Aa}}$ & $1,48^{\mathrm{Ab}}$ & $1,68^{\mathrm{Aa}}$ & $1,63^{\mathrm{Aa}}$ & $1,64^{\mathrm{Aa}}$ \\
\hline $\mathrm{TR}_{6}$ & $1,55^{\mathrm{Ab}}$ & $1,66^{\mathrm{Aa}}$ & $1,54^{\mathrm{Ab}}$ & $1,61^{\mathrm{Aa}}$ & $1,51^{\mathrm{Ab}}$ & $1,72^{\mathrm{Aa}}$ & $1,43^{\mathrm{Bb}}$ & $1,62^{\mathrm{Aa}}$ \\
\hline $\mathrm{TR}_{7}$ & $1,55^{\mathrm{Ab}}$ & $1,66^{\mathrm{Aa}}$ & $1,54^{\mathrm{Ab}}$ & $1,61^{\mathrm{Aa}}$ & $1,51^{\mathrm{Ab}}$ & $1,72^{\mathrm{Aa}}$ & $1,43^{\mathrm{Bb}}$ & $1,62^{\mathrm{Aa}}$ \\
\hline
\end{tabular}

$\mathrm{TR}_{1}, \mathrm{TR}_{2}, \mathrm{TR}_{3}, \mathrm{TR}_{4}, \mathrm{TR}_{5}, \mathrm{TR}_{6}, \mathrm{TR}_{7}$ : turnos de Rega de 1, 2, 3, 4, 5, 6 e 7 dias, respectivamente; $\mathrm{P}_{60}$ e $\mathrm{P}_{80}$ : população de 60.000 e 80.000 plantas ha-1, respectivamente; $D_{0}, D_{50}, D 1_{00}$ e $D_{200}$ :doses de adubação com 0, 50, 100 e $200 \mathrm{~kg} \mathrm{ha}^{-1}$ de fósforo, respectivamente. As médias seguidas de pelo menos uma mesma letra maiúscula na coluna ou minúscula na linha dentro de cada dose, não diferem entre si, pelo teste Tukey a 5\% de probabilidade. Fonte: Autores.

Quando foi realizada a comparação da AP entre os turnos de rega (TR) dentro de cada combinação de dose e população, pode-se observar que os TR apresentaram efeito significativo na AP na combinação entre $\mathrm{P}_{60}$ com a dose $\mathrm{D}_{0}$, sendo as maiores AP observadas nos $\mathrm{TR}_{2}, \mathrm{TR}_{4}, \mathrm{TR}_{6}$ e $\mathrm{TR}_{7}$. Comportamento semelhante foi evidenciado nas combinações da $\mathrm{P}_{60}$ e da $\mathrm{P}_{80}$ com a dose $\mathrm{D}_{200}$, sendo os maiores valores de $\mathrm{AP}$ nos $\mathrm{TR}_{1}, \mathrm{TR}_{3}$ e $\mathrm{TR}_{5}$.

O maior valor médio de AP encontrado foi 2,82 m para a dose $100 \mathrm{~kg} \mathrm{ha}^{-1}$ de $\mathrm{P}_{2} \mathrm{O}_{5}$ na $\mathrm{P}_{80}$. Já o menor valor médio de AP encontrado foi 2,50 m para a dose de $200 \mathrm{~kg} \mathrm{ha}^{-1}$ de $\mathrm{P}_{2} \mathrm{O}_{5}$ na $\mathrm{P}_{60}$. Entretanto, num sistema produtivo plantas altas ficam mais susceptíveis ao tombamento, o que dificulta a colheita mecanizada e expõe as espigas à ação de roedores e ao apodrecimento pelo contato com o solo (Costa et al., 2010). 
Considerando as combinações de doses de adubação e TR, pode-se observar que a AP foi maior na $\mathrm{P}_{80}$ que na $\mathrm{P}_{60}$, exceto para os turnos de rega $\mathrm{TR}_{2}, \mathrm{TR}_{4}, \mathrm{TR}_{6} \mathrm{e} \mathrm{TR}_{7}$ com a $\mathrm{D}_{0}$. Isso pode ser devido ao mecanismo que a planta utiliza quando sofre competição por luz, por exemplo, em plantios adensados, onde o seu crescimento é induzido na busca pela luz acima das plantas vizinhas. De acordo com Portugal et al. (2017), em estudo com milho em Selvíria, MT, onde há menor número de plantas numa mesma área, ocorre menor crescimento, em contrapartida, onde há maior número de plantas, ocorre o estiolamento, pelo maior crescimento que ocorre devido a necessidade de luz para a realizar fotossíntese. Em outro trabalho, Von Pinho et al. (2008), constataram relações lineares positivas para a altura de plantas com o aumento da densidade, sendo que, para um aumento de mil plantas na densidade, houve acréscimo de 0,20 $\mathrm{m}$ na altura de plantas.

Para Soares et al. (2012), os componentes de produção do milho estão diretamente relacionados com a disponibilidade de água no solo, tanto que em seus estudos constataram que algumas características como a altura de planta $(1,75$ e 1,88 m em condições de menor e maior disponibilidade hídricas, respectivamente), aumentam quando as plantas não sofrem estresse hídrico. Foi o que ocorreu neste trabalho com os valores desta pesquisa, apresentando valores superiores a 2,50 m se comparados aos citados acima.

Na comparação do diâmetro do colmo entre os TR dentro de cada combinação de dose de adubação e população, pode-se observar que os TR apresentaram efeito significativo no DC nas combinações entre dose e população, exceto para $\mathrm{P}_{80}$ na dose $\mathrm{D}_{100}$ e $\mathrm{P}_{60}$ nas doses $\mathrm{D}_{50}$ e $\mathrm{D}_{200}$. Em estudos com a cultura do milho, Galindo et al. (2017), observaram que a altura das plantas é influenciada pela densidade populacional, onde quanto maior a densidade populacional menor o diâmetro do colmo e maior altura, resultando em decréscimo de matéria seca individual, como resultado da competição entre as plantas pelos recursos do meio. Tais resultados corroboram com os encontrados neste trabalho.

Pode ser observado que nas combinações $\mathrm{D}_{0}$ e $\mathrm{D}_{50}$ com $\mathrm{P}_{80}$, o DC tende a decrescer com o aumento dos intervalos entre irrigação, sendo maior no $\mathrm{TR}_{1}$ e menor no $\mathrm{TR}_{7}$. Uma possível explicação para isso pode ser a deficiência em fósforo, ao se tratar das menores dosagens deste no solo, associada com períodos crescentes sem irrigação. Segundo Demétrio et al. (2008), o DC tem relação positiva com a resistência das plantas ao acamamento, ou seja, quanto menor o diâmetro menor a resistência ao tombamento, fator que pode refletir em perdas durante a colheita.

Considerando as combinações de dose de adubação e TR, pode-se observar que não houve efeito significativo na característica DC entre $\mathrm{P}_{60}$ e $\mathrm{P}_{80}$, exceto para os $\mathrm{TR}_{1}$ e $T R_{3}$ para a dose $\mathrm{D}_{0}, \mathrm{TR}_{2}, \mathrm{TR}_{3}$ e $\mathrm{TR}_{7}$ para a dose $\mathrm{D}_{50}, \mathrm{TR}_{3}$ para a dose $\mathrm{D}_{100}$ e $\mathrm{TR}_{2}, \mathrm{TR}_{3}$ e $\mathrm{TR}_{6}$ para a dose $\mathrm{D}_{200}$.

Analisando os valores médios das alturas de inserção de espigas, observa-se que não houve diferença significativa entre os TR nas populações estudadas, exceto na dose $\mathrm{D}_{200}$ com a população $\mathrm{P}_{60}$. Com a referida dosagem, na população de 60.000 plantas ha-1 ${ }^{-1}$ os $\mathrm{TR}_{2}, \mathrm{TR}_{4}, \mathrm{TR}_{6}$ e $\mathrm{TR}_{7}$ apresentaram menores alturas de inserção de espiga, o que coincide com os tratamentos que resultaram nas menores alturas de plantas.

Para a mesma dose e turno de rega, a AIE apresentou maiores valores médios em $\mathrm{P}_{80}$, excetuando-se o $\mathrm{TR}_{1}, \mathrm{TR}_{3}$ e $\mathrm{TR}_{5}$ na $\mathrm{D}_{200}$, os quais não apresentaram efeito significativo para esta característica. Em experimento com diferentes híbridos, Klein et al. (2018) concluíram, que a altura da inserção da espiga varia de acordo com as variações na altura de plantas, evidenciando a alta correlação entre essas variáveis.

Em trabalho com milho no estado de Minas Gerais, Uate et al. (2015), encontraram resultados de altura das plantas menores do que as encontradas no presente experimento (1,54 m), assim como a altura das espigas que ficaram em torno de 0,8 $\mathrm{m}$, inferiores às obtidas neste trabalho. Com plantas mais baixas, a altura de inserção da espiga também foi menor (1,01 m), assemelhando-se aos encontrados por Paziani et al. (2009), em São Paulo. 
Na Tabela 2 a seguir, estão apresentadas as comparações de médias para as características diâmetro de espigas (DE), comprimento de espigas (CE), número de fileiras de grãos (NF) e número de grãos na fileira (NGF) para o milho segunda safra no ano de 2017.

Tabela 2 - Valores médios parra características biométricas na colheita nas combinações dos níveis turno de rega, população de plantas e doses de adubação com fósforo.

\begin{tabular}{|c|c|c|c|c|c|c|c|c|}
\hline \multirow{2}{*}{$\begin{array}{c}\text { Turno de } \\
\text { Rega }\end{array}$} & \multicolumn{2}{|c|}{$\mathrm{D}_{0}$} & \multicolumn{2}{|c|}{ D50 } & \multicolumn{2}{|c|}{ D10 } & \multicolumn{2}{|c|}{ D200 } \\
\hline & $\mathrm{P}_{60}$ & $\mathrm{P}_{80}$ & $\mathrm{P}_{60}$ & $\mathrm{P}_{80}$ & $\mathrm{P}_{60}$ & $\mathrm{P}_{80}$ & $\mathrm{P}_{60}$ & $\mathrm{P}_{80}$ \\
\hline \multicolumn{9}{|c|}{ diâmetro de espigas (DE) (cm) } \\
\hline $\mathrm{TR}_{1}$ & $5,56^{\mathrm{Aa}}$ & $4,99^{\mathrm{Aa}}$ & $5,61^{\mathrm{Aa}}$ & $5,15^{\mathrm{Aa}}$ & $5,57^{\mathrm{Aa}}$ & $5,05^{\mathrm{Aa}}$ & $5,37^{\mathrm{Aa}}$ & $5,06^{\text {Aa }}$ \\
\hline $\mathrm{TR}_{2}$ & $5,54^{\mathrm{Aa}}$ & $5,06^{\text {Aa }}$ & $5,46^{\mathrm{Aa}}$ & $5,16^{\mathrm{Aa}}$ & $5,56^{\text {Aa }}$ & $5,06^{\mathrm{Aa}}$ & $5,39^{\text {Aa }}$ & $5,08^{\text {Aa }}$ \\
\hline $\mathrm{TR}_{3}$ & $5,33^{\mathrm{Aa}}$ & 4,91 Аа & $5,42 \mathrm{Aa}$ & $4,98^{\mathrm{Aa}}$ & $5,43 \mathrm{Aa}$ & $5,00^{\mathrm{Aa}}$ & $5,35^{\mathrm{Aa}}$ & $5,01^{\mathrm{Aa}}$ \\
\hline $\mathrm{TR}_{4}$ & $5,31^{\mathrm{Aa}}$ & 4,93 Аа & $5,44^{\mathrm{Aa}}$ & $5,01^{\mathrm{Aa}}$ & $5,42^{\mathrm{Aa}}$ & $4,93 \mathrm{Aa}$ & $5,36^{\text {Аa }}$ & $4,96^{\text {Aa }}$ \\
\hline $\mathrm{TR}_{5}$ & $5,33^{\mathrm{Aa}}$ & $5,01^{\mathrm{Aa}}$ & $5,29^{\mathrm{Aa}}$ & $5,01^{\mathrm{Aa}}$ & $5,38^{\text {Aa }}$ & $4,94^{\mathrm{Aa}}$ & $5,36^{\text {Aa }}$ & $5,07^{\mathrm{Aa}}$ \\
\hline $\mathrm{TR}_{6}$ & $5,32^{\mathrm{Aa}}$ & $5,10^{\mathrm{Aa}}$ & $5,27^{\mathrm{Aa}}$ & $5,04^{\mathrm{Aa}}$ & $5,41^{\mathrm{Aa}}$ & $5,02^{\mathrm{Aa}}$ & $5,33^{\mathrm{Aa}}$ & 5,04 Аa \\
\hline $\mathrm{TR}_{7}$ & $5,12^{\mathrm{Aa}}$ & $4,93 \mathrm{Aa}$ & 5,27 Аа & $5,00^{\mathrm{Aa}}$ & $5,35^{\mathrm{Aa}}$ & $4,85^{\text {Аa }}$ & $5,09^{\text {Аа }}$ & $4,90^{\mathrm{Aa}}$ \\
\hline \multicolumn{9}{|c|}{ comprimento de espigas (CE) (cm) } \\
\hline $\mathrm{TR}_{1}$ & $17,63^{\mathrm{ABa}}$ & $15,20^{\mathrm{Ab}}$ & $17,77^{\mathrm{Aa}}$ & $16,46^{\mathrm{Ab}}$ & $18,07^{\mathrm{ABa}}$ & $14,70^{\mathrm{Ab}}$ & $17,51^{\mathrm{Aa}}$ & $15,98^{\mathrm{Ab}}$ \\
\hline $\mathrm{TR}_{2}$ & $17,79^{\mathrm{Aa}}$ & $15,68^{\mathrm{Ab}}$ & $17,33^{\mathrm{Aa}}$ & $16,37^{\mathrm{Ab}}$ & $18,39^{\text {Аа }}$ & $15,38^{\mathrm{Ab}}$ & $17,52^{\mathrm{Aa}}$ & $16,21^{\mathrm{Ab}}$ \\
\hline $\mathrm{TR}_{3}$ & $16,92^{\mathrm{ABCa}}$ & $15,05^{\mathrm{Ab}}$ & $17,12^{\mathrm{Aa}}$ & $15,65^{\mathrm{Ab}}$ & $17,43^{\mathrm{ABa}}$ & $15,26^{\mathrm{Ab}}$ & $17,31^{\mathrm{Aa}}$ & $15,50^{\mathrm{Ab}}$ \\
\hline $\mathrm{TR}_{4}$ & $16,95^{\mathrm{ABCa}}$ & $15,11^{\mathrm{Ab}}$ & $16,98^{\mathrm{Aa}}$ & $15,87^{\mathrm{Ab}}$ & $17,27^{\mathrm{ABa}}$ & $15,34^{\mathrm{Ab}}$ & $17,50^{\mathrm{Aa}}$ & $15,70^{\mathrm{Ab}}$ \\
\hline $\mathrm{TR}_{5}$ & $16,51^{\mathrm{BCa}}$ & $15,88^{\mathrm{Aa}}$ & $17,37^{\mathrm{Aa}}$ & $15,63^{\mathrm{Ab}}$ & $17,28^{\mathrm{ABa}}$ & $15,56^{\mathrm{Ab}}$ & $17,20 \mathrm{ABa}$ & $15,54^{\mathrm{Ab}}$ \\
\hline $\mathrm{TR}_{6}$ & $17,13^{\mathrm{ABCa}}$ & $15,64^{\mathrm{Ab}}$ & 17,01 Aa & $16,12^{\mathrm{Ab}}$ & $17,73^{\mathrm{ABa}}$ & $15,60^{\mathrm{Ab}}$ & $17,32^{\mathrm{Aa}}$ & $15,81^{\mathrm{Ab}}$ \\
\hline $\mathrm{TR}_{7}$ & $16,25^{\mathrm{Ca}}$ & $14,95^{\mathrm{Ab}}$ & $17,08^{\mathrm{Aa}}$ & $15,35^{\mathrm{Ab}}$ & $17,02^{\mathrm{Ba}}$ & $14,86^{\mathrm{Ab}}$ & $16,01 \mathrm{Ba}$ & 15,22 Аa \\
\hline \multicolumn{9}{|c|}{ número de fileiras de grãos (NF) } \\
\hline $\mathrm{TR}_{1}$ & $18,12^{\mathrm{Aa}}$ & $17,25^{\text {Аa }}$ & $18,37^{\mathrm{Aa}}$ & $17,50^{\mathrm{Aa}}$ & $17,25^{\mathrm{Aa}}$ & $17,87^{\mathrm{Aa}}$ & $17,62^{\mathrm{Aa}}$ & $17,12^{\mathrm{Aa}}$ \\
\hline $\mathrm{TR}_{2}$ & $17,87^{\text {Аa }}$ & $17,62 \mathrm{Aa}$ & $17,75^{\mathrm{Aa}}$ & $17,00^{\mathrm{Aa}}$ & $17,50^{\mathrm{Aa}}$ & $17,50^{\text {Aa }}$ & $17,50^{\mathrm{Aa}}$ & $17,00^{\mathrm{Aa}}$ \\
\hline $\mathrm{TR}_{3}$ & $17,31^{\mathrm{Aa}}$ & 17,37 Аa & $17,50^{\mathrm{Aa}}$ & $17,00^{\mathrm{Aa}}$ & 17,87 Аа & 17,37 Аа & $17,50^{\mathrm{Aa}}$ & $17,37^{\mathrm{Aa}}$ \\
\hline $\mathrm{TR}_{4}$ & $17,56^{\mathrm{Aa}}$ & 17,25 Аа & $17,37^{\mathrm{Aa}}$ & $17,56^{\mathrm{Aa}}$ & $17,62 \mathrm{Aa}$ & $17,00^{\text {Аа }}$ & $17,50^{\mathrm{Aa}}$ & 16,93 Аа \\
\hline $\mathrm{TR}_{5}$ & $17,25^{\mathrm{Aa}}$ & $17,25^{\mathrm{Aa}}$ & $17,37^{\mathrm{Aa}}$ & $17,87^{\mathrm{Aa}}$ & $17,62^{\mathrm{Aa}}$ & $16,50^{\mathrm{Ab}}$ & $17,50^{\mathrm{Aa}}$ & $17,00^{\mathrm{Aa}}$ \\
\hline $\mathrm{TR}_{6}$ & $18,18^{\mathrm{Aa}}$ & $17,62 \mathrm{Aa}$ & $17,50^{\mathrm{Aa}}$ & $17,12^{\mathrm{Aa}}$ & $17,50^{\mathrm{Aa}}$ & $16,50^{\text {Аa }}$ & $17,25^{\mathrm{Aa}}$ & $16,75^{\text {Aa }}$ \\
\hline $\mathrm{TR}_{7}$ & $17,50^{\mathrm{Aa}}$ & $17,62^{\mathrm{Aa}}$ & $17,68^{\mathrm{Aa}}$ & $17,50^{\mathrm{Aa}}$ & $17,50^{\text {Аа }}$ & $16,75^{\text {Аa }}$ & $17,25^{\mathrm{Aa}}$ & $17,25^{\text {Аа }}$ \\
\hline \multicolumn{9}{|c|}{ número de grãos na fileira (NGF) } \\
\hline $\mathrm{TR}_{1}$ & $37,93 \mathrm{Aa}$ & $33,12^{\mathrm{Ab}}$ & 37,37 Аa & $35,50^{\mathrm{Aa}}$ & $39,25 \mathrm{Aa}$ & $33,06^{\mathrm{Ab}}$ & $38,56^{\mathrm{Aa}}$ & $35,68^{\mathrm{Ab}}$ \\
\hline $\mathrm{TR}_{2}$ & 37,68 Аa & $34,37^{\mathrm{Ab}}$ & $36,37^{\mathrm{Aa}}$ & $35,37^{\text {Аа }}$ & $38,43^{\text {Аа }}$ & $33,43^{\mathrm{Ab}}$ & $38,18^{\mathrm{ABa}}$ & $34,68^{\mathrm{ABa}}$ \\
\hline $\mathrm{TR}_{3}$ & $36,68^{\mathrm{Aa}}$ & $31,56^{\mathrm{Ab}}$ & 36,93 Аa & $34,25^{\mathrm{Ab}}$ & $37,31^{\mathrm{Aa}}$ & $33,68^{\mathrm{Ab}}$ & $36,62^{\mathrm{ABa}}$ & $32,25^{\mathrm{Bb}}$ \\
\hline $\mathrm{TR}_{4}$ & $37,18^{\mathrm{Aa}}$ & $34,18 \mathrm{Ab}$ & $37,31^{\mathrm{Aa}}$ & $35,56^{\mathrm{Aa}}$ & $37,25^{\mathrm{Aa}}$ & $34,00^{\mathrm{Ab}}$ & $38,37^{\mathrm{Aa}}$ & $35,25 \mathrm{ABb}$ \\
\hline $\mathrm{TR}_{5}$ & $36,50^{\mathrm{Aa}}$ & 34,62 Аa & $38,18^{\mathrm{Aa}}$ & $34,37^{\mathrm{Ab}}$ & 37,37 Аa & $33,31^{\mathrm{Ab}}$ & $37,31^{\mathrm{ABa}}$ & $34,43 \mathrm{ABb}$ \\
\hline $\mathrm{TR}_{6}$ & $38,37^{\mathrm{Aa}}$ & $33,56^{\mathrm{Ab}}$ & $37,12^{\mathrm{Aa}}$ & $34,81^{\mathrm{Ab}}$ & $39,18^{\mathrm{Aa}}$ & $33,81^{\mathrm{Ab}}$ & $38,12^{\mathrm{ABa}}$ & $34,81^{\mathrm{ABb}}$ \\
\hline $\mathrm{TR}_{7}$ & $35,87^{\text {Аа }}$ & $33,68^{\mathrm{Ab}}$ & $38,31^{\mathrm{Aa}}$ & $33,3^{\mathrm{Ab}}$ & 37,37 Аа & $33,62^{\mathrm{Ab}}$ & $35,06^{\mathrm{Ba}}$ & $33,93^{\mathrm{ABa}}$ \\
\hline
\end{tabular}

$\mathrm{TR}_{1}, \mathrm{TR}_{2}, \mathrm{TR}_{3}, \mathrm{TR}_{4}, \mathrm{TR}_{5}, \mathrm{TR}_{6}, \mathrm{TR}_{7}$ : turnos de Rega de 1, 2, 3, 4, 5, 6 e 7 dias, respectivamente; $\mathrm{P}_{60}$ e $\mathrm{P}_{80}$ : população de 60.000 e 80.000 plantas ha-1, respectivamente; $\mathrm{D}_{0}, \mathrm{D}_{50}, \mathrm{D}_{00}$ e $\mathrm{D}_{20} 0$ :doses de adubação com $0,50,100$ e $200 \mathrm{~kg} \mathrm{ha}^{-1}$ de fósforo, respectivamente. As médias seguidas de pelo menos uma mesma letra maiúscula na coluna e minúscula na linha para cada dose, não diferem entre si, pelo teste Tukey a 5\% de probabilidade. Fonte: Autores. 
Para o DE não foi verificado efeito significativo do TR em nenhuma das combinações de dose de adubação e população, ou seja, as diferentes frequências de irrigação não foram capazes de alterar o diâmetro de espiga. Considerando as combinações de dose de adubação e TR, pode-se observar que os valores médios de DE não apresentaram efeito significativo das populações de cultivo, exceto para a dose de adubo $\mathrm{D}_{0}$ e turno de rega $\mathrm{TR}_{5}$, onde o valor médio da $\mathrm{P}_{60}$ foi estatisticamente maior que em $\mathrm{P}_{80}$.

Foi verificado que o TR não apresentou efeito significativo no $\mathrm{CE}$ nenhuma das doses de adubação fosfatada na população $\mathrm{P}_{80}$, assim como na $\mathrm{P}_{60}$ com a $\mathrm{D}_{50}$. Por outro lado, na $\mathrm{P}_{60}$ com a $\mathrm{D}_{0}, \mathrm{D}_{100}$ e $\mathrm{D}_{200}$ o efeito do TR foi verificado, sendo menores comprimentos de espigas observados no $\mathrm{TR}_{7}$.

Comparando os valores médios de CE entre $\mathrm{P}_{60}$ e $\mathrm{P}_{80}$, numa mesma dose, evidenciou-se que a população $\mathrm{P}_{80}$ apresentou menor $C E$ na maioria dos $T R$, excetuando-se apenas $\mathrm{D}_{0}$ no $\mathrm{TR}_{5}$ e $\mathrm{D}_{200}$ no $\mathrm{TR}_{7}$. De forma prática, menor comprimento de espigas resulta em uma menor quantidade de grãos produzidos por espiga ou em grãos menores. Em ambos os casos, esta redução do comprimento de espiga é desfavorável, pois culminará em menor produção por unidade de área.

Para o NF de grãos na espiga, não foi verificado efeito significativo do TR em nenhuma das combinações de dose e população, ou seja, as diferentes frequência de irrigação não foram capazes de alterar o número de fileiras de grãos na espiga. Comparando os valores médios de NF entre as $\mathrm{P}_{60}$ e $\mathrm{P}_{80}$, para a mesma dose e turno de rega, verificou-se que não houve efeito significativo da densidade de plantio, exceto para $\mathrm{D}_{100}$ no $\mathrm{TR}_{5}$.

Também não foi verificado efeito do TR nas combinações de $\mathrm{D}_{0}, \mathrm{D}_{50}$ e $\mathrm{D}_{100}$ para o NGF em nenhuma das populações. No entanto, na $\mathrm{D}_{200}$, em ambas as populações, este efeito foi evidenciado. Independentemente da combinação de TR e dose de adubação, a $\mathrm{P}_{60}$ apresentou maior NGF, excetuando se apenas as combinações $\mathrm{D}_{0}$ com $\mathrm{TR}_{5}, \mathrm{D}_{50}$ com $\mathrm{TR}_{1}, \mathrm{TR}_{2}$ e $\mathrm{TR}_{4}$ e $\mathrm{D}_{200}$ com $\mathrm{TR}_{2}$ e $\mathrm{TR}_{7}$, cujo NGF foram iguais estatisticamente em ambas as populações. Vian et al. (2016), em estudo da variabilidade da produtividade do milho na região do Planalto Médio do estado do Rio Grande do Sul, obtiveram valores médios de NF e NGF iguais a 12,9 e 36,4 respectivamente, para a safra 2010/2011 e 13,3 e 38,2 respectivamente, para a safra 2011/2012. Estes valores são semelhantes aos encontrados no presente trabalho (Tabela 2).

$\mathrm{Na}$ Tabela 3 estão apresentadas as comparações de médias para as características massa de 1000 grãos $\left(\mathrm{P}_{1000}\right)$ e índice de colheita (IC) para a cultura do milho segunda safra no ano de 2017. 
Tabela 3 - Valores médios das características agronômicas para as combinações dos níveis turno de rega, população de plantas e doses de adubação com fósforo.

D0

Turno de Rega
D50

$\overline{\mathrm{P}_{60}} \quad \mathrm{P}_{80}$

D10

$\mathrm{P}_{60} \quad \mathrm{P}_{80}$
$\mathrm{P}_{60}$

$\mathrm{P}_{80}$
D200

$\mathrm{P}_{60} \quad \mathrm{P}_{80}$

\begin{tabular}{|c|c|c|c|c|c|c|c|c|}
\hline \multicolumn{9}{|c|}{ massa de 1000 grãos (P1000) (g) } \\
\hline $\mathrm{TR}_{1}$ & $319,1^{\mathrm{ABa}}$ & $283,3^{\mathrm{ABb}}$ & $336,8^{\mathrm{Aa}}$ & $285,7^{\mathrm{ABb}}$ & $388,8^{\mathrm{Aa}}$ & $261,1^{\mathrm{Bb}}$ & $311,4^{\mathrm{Aa}}$ & $280,0^{\mathrm{Ab}}$ \\
\hline $\mathrm{TR}_{2}$ & $333,7^{\mathrm{Aa}}$ & $291,7^{\mathrm{ABb}}$ & $322,2^{\mathrm{Aa}}$ & $306,9^{\mathrm{Aa}}$ & $343,1^{\mathrm{Aa}}$ & $279,8^{\mathrm{ABb}}$ & $331,9^{\mathrm{Aa}}$ & $305,1^{\mathrm{Ab}}$ \\
\hline $\mathrm{TR}_{3}$ & $315,9^{\mathrm{ABa}}$ & $260,1^{\mathrm{Bb}}$ & $329,9^{\mathrm{Aa}}$ & $277,7^{\mathrm{ABb}}$ & $236,3^{\mathrm{Aa}}$ & $273,9^{\mathrm{ABb}}$ & $329,4^{\mathrm{Aa}}$ & $279,6^{\mathrm{Ab}}$ \\
\hline $\mathrm{TR}_{4}$ & $311,2^{\mathrm{ABa}}$ & $289,0^{\mathrm{ABa}}$ & $318,7^{\mathrm{Aa}}$ & $288,1^{\mathrm{ABb}}$ & $337,2^{\mathrm{Aa}}$ & $289,9^{\mathrm{ABb}}$ & $328,3^{\mathrm{Aa}}$ & $297,6^{\mathrm{Ab}}$ \\
\hline $\mathrm{TR}_{5}$ & $295,0^{\mathrm{Ba}}$ & $279,2^{\mathrm{ABa}}$ & $317,7^{\mathrm{Aa}}$ & $264,4^{\mathrm{Bb}}$ & $318,8^{\mathrm{Aa}}$ & $287,1^{\mathrm{ABb}}$ & $324,0^{\mathrm{Aa}}$ & $282,8^{\mathrm{Ab}}$ \\
\hline $\mathrm{TR}_{6}$ & $305,2^{\mathrm{ABa}}$ & $299,9^{\mathrm{Aa}}$ & $309,9^{\mathrm{Aa}}$ & $306,1^{\mathrm{Aa}}$ & $332,4^{\mathrm{Aa}}$ & $299,0^{\mathrm{Ab}}$ & $334,0^{\mathrm{Aa}}$ & $313,3^{\mathrm{Ab}}$ \\
\hline $\mathrm{TR}_{7}$ & $310,0^{\mathrm{ABa}}$ & $286,2^{\mathrm{ABb}}$ & $317,7^{\mathrm{Aa}}$ & $300,4^{\mathrm{Aa}}$ & $332,8^{\mathrm{Aa}}$ & $292,8^{\mathrm{ABb}}$ & $311,9^{\mathrm{Aa}}$ & $283,6^{\mathrm{Ab}}$ \\
\hline \multicolumn{9}{|c|}{ índice de colheita (IC) } \\
\hline $\mathrm{TR}_{1}$ & $0,415^{\mathrm{Ba}}$ & $0,432^{\mathrm{Aa}}$ & $0,438^{\mathrm{Ba}}$ & $0,474^{\mathrm{Aa}}$ & $0,347^{\mathrm{Bb}}$ & $0,404^{\mathrm{Ba}}$ & $0,418^{\mathrm{Cb}}$ & $0,500^{\mathrm{Aa}}$ \\
\hline $\mathrm{TR}_{2}$ & $0,482^{\mathrm{Aa}}$ & $0,483^{\mathrm{Aa}}$ & $0,534^{\mathrm{Aa}}$ & $0,468^{\mathrm{Ab}}$ & $0,489^{\mathrm{Aa}}$ & $0,480^{\mathrm{Aa}}$ & $0,537^{\mathrm{Aa}}$ & $0,491^{\mathrm{Ab}}$ \\
\hline $\mathrm{TR}_{3}$ & $0,497^{\mathrm{Aa}}$ & $0,491^{\mathrm{Aa}}$ & $0,472^{\mathrm{ABa}}$ & $0,438^{\mathrm{Aa}}$ & $0,488^{\mathrm{Aa}}$ & $0,467^{\mathrm{Aba}}$ & $0,471^{\mathrm{BCa}}$ & $0,494^{\mathrm{Aa}}$ \\
\hline $\mathrm{TR}_{4}$ & $0,489^{\text {Aa }}$ & $0,488^{\mathrm{Aa}}$ & $0,491^{\mathrm{ABa}}$ & $0,466^{\mathrm{Aa}}$ & $0,501^{\mathrm{Aa}}$ & $0,463^{\mathrm{Aba}}$ & $0,491^{\mathrm{ABa}}$ & $0,496^{\mathrm{Aa}}$ \\
\hline $\mathrm{TR}_{5}$ & $0,487^{\mathrm{Aa}}$ & $0,456^{\mathrm{Aa}}$ & $0,478^{\mathrm{ABa}}$ & $0,457^{\mathrm{Aa}}$ & $0,498^{\mathrm{Aa}}$ & $0,467^{\mathrm{Aba}}$ & $0,487^{\mathrm{ABa}}$ & $0,384^{\mathrm{Bb}}$ \\
\hline $\mathrm{TR}_{6}$ & $0,495^{\mathrm{Aa}}$ & $0,475^{\mathrm{Aa}}$ & $0,504^{\mathrm{Aa}}$ & $0,474^{\mathrm{Aa}}$ & $0,510^{\mathrm{Aa}}$ & $0,481^{\mathrm{Aa}}$ & $0,507^{\mathrm{ABa}}$ & $0,482^{\mathrm{Aa}}$ \\
\hline $\mathrm{TR}_{7}$ & $0,490^{\mathrm{Aa}}$ & $0,469^{\mathrm{Aa}}$ & $0,500^{\mathrm{ABa}}$ & $0,477^{\mathrm{Aa}}$ & $0,494^{\mathrm{Aa}}$ & $0,466^{\mathrm{Aba}}$ & $0,476^{\mathrm{ABCa}}$ & $0,481^{\mathrm{Aa}}$ \\
\hline
\end{tabular}

$\mathrm{TR}_{1}, \mathrm{TR}_{2}, \mathrm{TR}_{3}, \mathrm{TR}_{4}, \mathrm{TR}_{5}, \mathrm{TR}_{6}, \mathrm{TR}_{7}$ : turnos de Rega de $1,2,3,4,5,6$ e 7 dias, respectivamente; $\mathrm{P}_{60}$ e $\mathrm{P}_{80}:$ população de 60.000 e 80.000 plantas ha-1, respectivamente; $\mathrm{D}_{0}, \mathrm{D}_{50}, \mathrm{D}_{00}$ e $\mathrm{D}_{20} 0$ :doses de adubação com $0,50,100$ e $200 \mathrm{~kg} \mathrm{ha}^{-1}$ de fósforo, respectivamente. As médias seguidas de pelo menos uma mesma letra maiúscula na coluna e minúscula na linha para cada dose, não diferem entre si, pelo teste Tukey a 5\% de probabilidade. Fonte: Autores.

Na comparação do $\mathrm{P}_{1000}$ entre os TR dentro de cada combinação de dose de adubação e população, pode-se observar que os TR apresentaram efeito significativo na $\mathrm{D}_{0}, \mathrm{D}_{50}$ e $\mathrm{D}_{100}$ na $\mathrm{P}_{80}$ e apenas $\mathrm{D}_{0}$ na $\mathrm{P}_{60}$. Nestes casos foram verificados que o $\mathrm{TR}_{2}$ e o $\mathrm{TR}_{6}$ proporcionaram maiores valores de massa de 1000 grãos nas populações $\mathrm{P}_{60}$ e $\mathrm{P}_{80}$, respectivamente. Considerando as combinações de dose de adubação e TR, pode-se observar que os valores médios de $\mathrm{P}_{1000}$ foram maiores na $\mathrm{P}_{60}$ que na $\mathrm{P}_{80}$, excetuando-se os $\mathrm{TR}_{4}, \mathrm{TR}_{5}$ e $\mathrm{TR}_{6}$ na $\mathrm{D}_{0}$ e $\mathrm{TR}_{2}, \mathrm{TR}_{6}$ e $\mathrm{TR}_{7}$ na $\mathrm{D}_{50}$, nos quais os resultados médios para esta característica não apresentaram diferença estatística.

Os resultados observados nesse estudo estão em concordância com os encontrados por Pereira et al. (2008), que também observaram na cultura do milho redução na massa de 1000 grãos com o aumento da população de plantas. Foloni et al. (2014), em pesquisa no norte do Paraná, encontraram comportamento semelhante, onde a massa de 1000 grãos decresceu linearmente com o aumento da população de plantas de milho. 
Na comparação do índice de colheita (IC) entre os TR dentro de cada combinação de dose de adubação e população, pode-se observar que na $\mathrm{P}_{80}$, nas doses $\mathrm{D}_{0}$ e $\mathrm{D}_{50}$, não foi verificado efeito significativo do TR. Por outro lado, os TR apresentaram efeito no IC na $\mathrm{P}_{60}$, nas $\mathrm{D}_{0}$ e $\mathrm{D}_{50}$, e em ambas as populações nas $\mathrm{D}_{100}$ e $\mathrm{D}_{200}$. Independentemente da combinação de TR e dose de adubação, na maioria das comparações, não houve diferença no IC entre as populações, excetuando-se apenas as combinações entre $\mathrm{D}_{50}$ com $\mathrm{TR}_{2}, \mathrm{D}_{100}$ com $\mathrm{TR}_{1}$ e $\mathrm{D}_{200}$ com $\mathrm{TR}_{1}, \mathrm{TR}_{2}$ e $\mathrm{TR}_{5}$. Considerando as combinações de dose de adubação e TR, pode-se observar que os índices de colheita foram maiores na população $\mathrm{P}_{60}$ para as doses $\mathrm{D}_{50}$ e $\mathrm{D}_{200}$ no $\mathrm{TR}_{2} \mathrm{e}$ $\mathrm{TR}_{5}$, respectivamente. No entanto, os IC foram maiores na $\mathrm{P}_{80}$ para a dose $\mathrm{D}_{100}$ no $\mathrm{TR}_{1}$ e para a dose $\mathrm{D}_{200}$ no $\mathrm{TR}_{1}$.

$\mathrm{Na}$ maioria dos turnos de rega, independentemente da população de plantas usada, observou-se que as variações na dose de adubação não afetaram as características biométricas nem agronômicas. As médias observadas estão apresentadas na Tabela 4 .

Tabela 4 - Valores médios para as características biométricas e agronômicas do milho em função da população e turno de rega.

\begin{tabular}{lcccccccccc}
\hline População & $\mathrm{TR}$ & $\mathrm{AP}$ & $\mathrm{DC}$ & $\mathrm{AIE}$ & $\mathrm{DE}$ & $\mathrm{CE}$ & $\mathrm{NF}$ & $\mathrm{NGF}$ & $\mathrm{P}_{1000}$ & $\mathrm{IC}$ \\
\hline $\mathrm{P}_{60}$ & $\mathrm{TR}_{1}$ & 2,603 & 2,389 & 1,546 & 5,528 & 17,751 & 17,843 & 38,281 & 343,436 & 0,405 \\
$\mathrm{P}_{60}$ & $\mathrm{TR}_{2}$ & 2,581 & 2,308 & 1,512 & 5,485 & 17,762 & 17,656 & 37,671 & 349,597 & 0,511 \\
$\mathrm{P}_{60}$ & $\mathrm{TR}_{3}$ & 2,603 & 2,206 & 1,546 & 5,381 & 17,200 & 17,546 & 36,890 & 334,215 & 0,482 \\
$\mathrm{P}_{60}$ & $\mathrm{TR}_{4}$ & 2,581 & 2,274 & 1,512 & 5,379 & 17,178 & 17,515 & 37,531 & 333,019 & 0,493 \\
$\mathrm{P}_{60}$ & $\mathrm{TR}_{5}$ & 2,603 & 2,335 & 1,546 & 6,078 & 17,184 & 17,437 & 37,343 & 330,180 & 0,488 \\
$\mathrm{P}_{60}$ & $\mathrm{TR}_{6}$ & 2,581 & 2,303 & 1,512 & 5,332 & 17,301 & 17,609 & 38,203 & 333,673 & 0,504 \\
$\mathrm{P}_{60}$ & $\mathrm{TR}_{7}$ & 2,581 & 2,235 & 1,512 & 5,231 & 16,595 & 17,484 & 36,656 & 329,788 & 0,490 \\
$\mathrm{P}_{80}$ & $\mathrm{TR}_{1}$ & 2,779 & 2,309 & 1,653 & 5,064 & 15,590 & 17,437 & 34,343 & 294,528 & 0,453 \\
$\mathrm{P}_{80}$ & $\mathrm{TR}_{2}$ & 2,736 & 2,346 & 1,660 & 5,096 & 15,915 & 17,281 & 34,468 & 306,929 & 0,481 \\
$\mathrm{P}_{80}$ & $\mathrm{TR}_{3}$ & 2,779 & 2,445 & 1,653 & 4,978 & 15,368 & 17,281 & 32,937 & 281,251 & 0,472 \\
$\mathrm{P}_{80}$ & $\mathrm{TR}_{4}$ & 2,736 & 2,246 & 1,660 & 4,959 & 15,507 & 17,171 & 34,750 & 304,616 & 0,478 \\
$\mathrm{P}_{80}$ & $\mathrm{TR}_{5}$ & 2,779 & 2,305 & 1,653 & 5,009 & 15,656 & 17,156 & 34,187 & 292,017 & 0,441 \\
$\mathrm{P}_{80}$ & $\mathrm{TR}_{6}$ & 2,736 & 2,261 & 1,660 & 5,053 & 15,795 & 17,093 & 34,250 & 318,551 & 0,478 \\
$\mathrm{P}_{80}$ & $\mathrm{TR}_{7}$ & 2,736 & 2,169 & 1,660 & 4,923 & 15,100 & 17,109 & 33,640 & 301,883 & 0,473 \\
\hline
\end{tabular}

$\mathrm{TR}, \mathrm{TR}_{1}, \mathrm{TR}_{2}, \mathrm{TR}_{3}, \mathrm{TR}_{4}, \mathrm{TR}_{5}, \mathrm{TR}_{6}, \mathrm{TR}_{7}$ : turnos de Rega de 1, 2, 3, 4, 5, 6 e 7 dias, respectivamente; $\mathrm{P}_{60}$ e $\mathrm{P}_{80}$ : população de 60.000 e 80.000 plantas ha-1, respectivamente; AP: altura de plantas $(\mathrm{m})$; DC diâmetro de colmo $(\mathrm{cm})$; AIE altura de inserção de espigas (m); DE: diâmetro de espigas (cm); CE: comprimento de espigas; NF: número de fileiras de grãos; NGF: número de grãos na fileira; P1000: massa de 1000 grãos (g); IC: índice de colheita, adimensional. Fonte: Autores.

Foi verificado que o CE e NGF não apresentaram efeito da adubação em nenhuma das combinações de TR e população. Nas demais características, nos casos em que foi verificado efeito da dose de adubação, ajustou-se as equações de regressão apresentadas na Tabela 5 . 
Tabela 5 - Valores estimados da constante e dos coeficientes de regressão das equações ajustadas para as características biométricas e agronômicas do milho.

\begin{tabular}{|c|c|c|c|}
\hline População & $\mathrm{TR}$ & Equações & $\begin{array}{c}\text { Coeficiente } \\
\left(\mathrm{R}^{2}\right)\end{array}$ \\
\hline \multicolumn{4}{|c|}{ altura de plantas (AP) (m) } \\
\hline $\mathrm{P}_{60}$ & $\mathrm{TR}_{1}$ & $\hat{\mathrm{Y}}=2,52+0,0009 \mathrm{D}$ & 0,67 \\
\hline $\mathrm{P}_{60}$ & $\mathrm{TR}_{2}$ & $\hat{\mathrm{Y}}=2,69-0,002 \mathrm{D}+0,000006 \mathrm{D}^{2}$ & 0,73 \\
\hline $\mathrm{P}_{60}$ & $\mathrm{TR}_{3}$ & $\hat{\mathrm{Y}}=2,52+0,0009 \mathrm{D}$ & 0,67 \\
\hline $\mathrm{P}_{60}$ & $\mathrm{TR}_{4}$ & $\hat{\mathrm{Y}}=2,69-0,002 \mathrm{D}+0,000006 \mathrm{D}^{2}$ & 0,73 \\
\hline $\mathrm{P}_{60}$ & $\mathrm{TR}_{5}$ & $\hat{\mathrm{Y}}=2,52+0,0009 \mathrm{D}$ & 0,67 \\
\hline $\mathrm{P}_{60}$ & $\mathrm{TR}_{6}$ & $\hat{\mathrm{Y}}=2,69-0,002 \mathrm{D}+0,000006 \mathrm{D}^{2}$ & 0,73 \\
\hline $\mathrm{P}_{60}$ & $\mathrm{TR}_{7}$ & $\hat{\mathrm{Y}}=2,69-0,002 \mathrm{D}+0,000006 \mathrm{D}^{2}$ & 0,73 \\
\hline \multicolumn{4}{|c|}{ diâmetro de colmo (DC) $(\mathrm{cm})$} \\
\hline $\mathrm{P}_{80}$ & $\mathrm{TR}_{6}$ & $\hat{\mathrm{Y}}=2,23-0,0016 \mathrm{D}+0,00001 \mathrm{D}^{2}$ & 0,82 \\
\hline \multicolumn{4}{|c|}{ altura de inserção de espigas (AIE) (m) } \\
\hline $\mathrm{P}_{60}$ & $\mathrm{TR}_{2}$ & $\hat{\mathrm{Y}}=1,56-0,0006 \mathrm{D}$ & 0,75 \\
\hline $\mathrm{P}_{60}$ & $\mathrm{TR}_{4}$ & $\hat{\mathrm{Y}}=1,56-0,0006 \mathrm{D}$ & 0,75 \\
\hline $\mathrm{P}_{60}$ & $\mathrm{TR}_{6}$ & $\hat{\mathrm{Y}}=1,56-0,0006 \mathrm{D}$ & 0,75 \\
\hline $\mathrm{P}_{60}$ & $\mathrm{TR}_{7}$ & $\hat{\mathrm{Y}}=1,56-0,0006 \mathrm{D}$ & 0,75 \\
\hline \multicolumn{4}{|c|}{ número de grãos na fileira (NFG) } \\
\hline $\mathrm{P}_{60}$ & $\mathrm{TR}_{7}$ & $\hat{\mathrm{Y}}=36,14+0,0411 \mathrm{D}-0,00023 \mathrm{D}^{2}$ & 0,26 \\
\hline $\mathrm{P}_{80}$ & $\mathrm{TR}_{5}$ & $\hat{\mathrm{Y}}=31,82+0,0459 \mathrm{D}-0,00022 \mathrm{D}^{2}$ & 0,26 \\
\hline \multicolumn{4}{|c|}{ diâmetro de espigas (DE) (cm) } \\
\hline $\mathrm{P}_{60}$ & $\mathrm{TR}_{7}$ & $\hat{\mathrm{Y}}=5,19+0,0003 \mathrm{D}+0,00002 \mathrm{D}^{2}$ & 0,72 \\
\hline \multicolumn{4}{|c|}{ índice de colheita (IC) } \\
\hline $\mathrm{P}_{80}$ & $\mathrm{TR}_{4}$ & $\hat{Y}=0,49-0,0006 \mathrm{D}+0,000003 \mathrm{D}^{2}$ & 0,54 \\
\hline \multicolumn{4}{|c|}{ massa de 1000 grãos (P1000) (g) } \\
\hline $\mathrm{P}_{60}$ & $\mathrm{TR}_{1}$ & $\hat{\mathrm{Y}}=319,60+0,0443 \mathrm{D}-0,00242 \mathrm{D}^{2}$ & 0,59 \\
\hline
\end{tabular}

$\mathrm{TR}_{1}, \mathrm{TR}_{2}, \mathrm{TR}_{3}, \mathrm{TR}_{4}, \mathrm{TR}_{5}, \mathrm{TR}_{6}, \mathrm{TR}_{7}$ : turnos de Rega de 1, 2, 3, 4, 5, 6 e 7 dias, respectivamente; $\mathrm{P}_{60}$ e $\mathrm{P}_{80}:$ população de 60.000 e 80.000 plantas ha ${ }^{-1}$, respectivamente. Fonte: Autores. 
Na característica AP foram obtidas equações de regressão linear significativa apenas na $\mathrm{P}_{60}$, sendo estas equações de primeiro grau nos $\mathrm{TR}_{1}, \mathrm{TR}_{3}$ e $\mathrm{TR}_{5}$ e de segundo grau nos $\mathrm{TR}_{2}, \mathrm{TR}_{4}, \mathrm{TR}_{6}$ e $\mathrm{TR}_{7}$. Nas combinações $\mathrm{P}_{60}$ com $\mathrm{TR}_{1}, \mathrm{TR}_{3}$ e $\mathrm{TR}_{5}$, quanto maior a dose de fósforo, maior a altura média das plantas. Interessantemente os $\mathrm{TR}_{2}, \mathrm{TR}_{4} \mathrm{e} \mathrm{TR}_{7}$ apresentaram o mesmo comportamento dos efeitos das doses de fósforo, ou seja, os mesmos valores dos parâmetros da regressão, sendo também observado que a altura média das plantas diminui com o aumento da dose até o valor mínimo de 2,52 m, atingido com a dose de 166,67 kg ha-1 de $\mathrm{P}_{2} \mathrm{O}_{5}$ e, a partir de então, a altura média das plantas elevou com o aumento da dose de fósforo.

Considerando a característica DC, apenas na combinação $\mathrm{P}_{80}$ com $\mathrm{TR}_{6}$ foi obtida equação de regressão significativa,

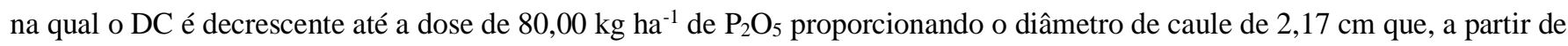
então, passa a ser crescente com o aumento da dose de fósforo.

$\mathrm{Na}$ AIE, apenas na $\mathrm{P}_{60}$, quando combinada com os $\mathrm{TR}_{2}, \mathrm{TR}_{4}, \mathrm{TR}_{6}$ e $\mathrm{TR}_{7}$ foram obtidas equações significativas, nas quais a AIE diminui linearmente com o aumento da dose de $\mathrm{P}_{2} \mathrm{O}_{5}$ aplicada. No DE, apenas foi verificado efeito quadrático da adubação na $\mathrm{P}_{60}$ com $\mathrm{TR}_{7}$. No NGF, apenas foi verificado efeito da adubação na $\mathrm{P}_{60}$ com $\mathrm{TR}_{7}$ e na $\mathrm{P}_{80}$ com $\mathrm{TR}_{5}$. O IC a produtividade foram constante ao longo das doses de adubação exceto na $\mathrm{P}_{80}$ com $\mathrm{TR}_{4}$ e $\mathrm{P}_{60}$ com $\mathrm{TR}_{1}$, respectivamente.

\section{Conclusão}

A população de 80 mil plantas ha ${ }^{-1}$ apresentou maior altura de plantas e de inserção de espigas, independente do turno de rega adotado e da dose de fósforo aplicada.

A população de 60 mil plantas ha ${ }^{-1}$, apresentou maior comprimento de espigas, número de grãos na fileira e massa de 1000 grãos.

Doses crescentes de fósforo, nos níveis estudados, afetaram as alturas de plantas e altura de inserção de espigas na população de 60 mil plantas ha ${ }^{-1}$. Já a população de 80 mil plantas ha $^{-1}$, doses crescentes de fósforo afetaram diâmetro de caule.

Não foi evidenciado efeito da adubação fosfatada nas características produtivas estudadas: índice de colheita, diâmetro de espigas, comprimento de espigas, número de fileiras de grãos, número de grãos na fileira e massa de 1.000 grãos.

Sugere-se mais estudos nesta área, pois a estatística multivariada pode agregar muitos conhecimentos na cultura do milho, e por isso, estudos nesta linha, com outros atributos podem ajudar no melhor entendimento da produção da cultura.

\section{Agradecimentos}

Este estudo foi financiado em parte pelo Coordenação de Aperfeiçoamento de Pessoal de Nível Superior - Brasil (CAPES) - Finance Code 001.

Este trabalho foi realizado com o apoio de CNPq, Conselho Nacional de Desenvolvimento Científico e Tecnológico Brazil. 141231/2019-0.

À Fundação Arthur Bernardes (FUNARBE), pelo apoio financeiro para publicação deste trabalho. À Universidade Federal do Mato Grosso do Sul (UFMS, Chapadão do Sul, MS) e à Universidade Federal de Viçosa (UFV, Viçosa, MG).

\section{Referências}

Ahmadipour, A., Shaibani, P. \& Mostafavi, S.A. (2019). Assessment of empirical methods for estimating potential evapotranspiration in Zabol Synoptic Station by REF-ET model. Medbiotech Journal, 3 (01), 1 - 4. 10.22034/MBT.2019.80823.

Conab - Companhia Nacional de Abastecimento. (2020). Acompanhamento da safra brasileira de grãos, v. 7 - Safra $2019 / 20$ - Décimo primeiro levantamento, Brasília, p. 1-62, agosto 2020. ISSN 2318 - 6852. https://www.conab.gov.br/info-agro/safras/graos/boletim-da-safra-de-graos.

Demétrio, C. S., Filho, D. F., Cazetta, J. O. \& Cazetta, D. A. (2008). Desempenho de híbridos de milho submetidos a diferentes espaçamentos e densidades populacionais. Pesquisa Agropecuária Brasileira, Brasília, DF, 43(12), 1691 - 1697. https://doi.org/10.1590/S0100-204X2008001200008. 
Embrapa - Empresa Brasileira de Pesquisa Agropecuária. (2017). Manual de métodos de análise de solo. (3a ed.), rev. e ampl. Brasília, DF: Embrapa. http://www.infoteca.cnptia.embrapa.br/infoteca/handle/doc/1085209.

Foloni, J. S. S., Calonego, J. C., Catuchi, T. A., Belleggia, N. A., Tiritan, C. S. \& Barbosa, A. M. (2014). Cultivares de milho em diferentes populações de plantas com espaçamento reduzido na safrinha. Revista Brasileira de Milho e Sorgo, 13(3), 312 - 325. http://dx.doi.org/10.18512/1980-6477/rbms.v13n3p312325 .

Galindo, F. H., Zocoler, J. L., Filho, M. C. M. T., Santini, J. M. K., Ludkiewicz, M. G. Z. \& Buzetti, S. (2017). Teor de água nos grãos, em ocasião de colheita nas perdas ocorridas no milho. Cultura Agronômica, Ilha Solteira, 26(4), 671 - 682. https://search.proquest.com/docview/2173178801?.

Klein, J. L., Viana, A. F. P., Martini, P. M., Adams, S. M., Guzatto, C., Bona, R. A., Rodrigues, L. S., Filho, D. C. A. \& Brondani, I. L. (2018). Desempenho produtivo de híbridos de milho para a produção de silagem da planta inteira. Revista Brasileira de Milho e Sorgo, 17(1), 101 - 110. https://doi.org/10.18512/1980-6477/rbms.v17n1p101-110.

Mangili, F. B. \& Ely, D. F. (2014). Influência das chuvas na produção de milho safrinha em Londrina-PR. Geographia Opportuno Tempore, 1 (2), 153 - 164. http://www.uel.br/revistas/uel/index.php/Geographia/article/view/20287.

Oliveira, J. T., Ribeiro, I. S., Roque, C. G., Montanari, R., Gava, R. \& Teodoro, P. E. (2018). Contribution of morphological traits for grain yield in common bean. Bioscience Journal, 34,. 951 - 956. https://doi.org/10.14393/BJ-v34n2a2018-39701.

Oliveira, J. T., Oliveira, R. A., Puiatti, M., Teodoro, P. E. \& Montanari, R. (2020a). Spatial Analysis and Mapping of the Effect of Irrigation and Nitrogen Application on Lateral Shoot Growing of Garlic. HortScience, 55, 1 - 2. https://doi.org/10.21273/HORTSCI14881-20.

Oliveira, J. T., Oliveira, R. A., Cunha, F. F., Ribeiro, I. S., Oliveira, L. A. A. \& Teodoro, P. E. (2020b). Contribution of Morphological Variables in Garlic Bulb Yield. HortScience, 55 (6), 896 - 897. https://doi.org/10.21273/HORTSCI14996-20.

Paziani, S. D. F., Duarte, A. P., Nussio, L. G., Gallo, P. B., Bittar, C. M. M., Zopollatto, M. \& Reco, P. C. (2009). Características agronômicas e bromatológicas de híbridos de milho para produção de silagem. Revista Brasileira de Zootecnia, Viçosa, MG, 38(3), 411 - 417. https://doi.org/10.1590/S151635982009000300002

Pereira, F. R., Cruz, S., Alburqueque, A. W., Santos, J. R. \& Silva, E. T. (2008). Arranjo espacial de plantas de milho em sistema plantio direto. Revista Brasileira de Engenharia Agrícola e Ambiental, p. 69 - 74. https://doi.org/10.1590/S1415-43662008000100010.

Portugal, J. R., Arf, O., Peres, A. R., Gitti, D. C. \& Garcia, N. F. S. (2017). Coberturas vegetais, doses de nitrogênio e inoculação com Azospirillum brasilense em milho no Cerrado. Revista Ciência Agronômica, 48(4),. 639 - 649. https://doi.org/10.5935/1806-6690.20170074.

Ribeiro, A. C., Guimarães, P. T. G. \& Alvarez, V. V. H. (1999). Recomendação para o uso de corretivos e fertilizantes em Minas Gerais: 5. Aproximação. Viçosa: Comissão de Fertilidade do Solo do Estado de Minas Gerais. 359 p. https://www.editoraufv.com.br/produto/5-aproximacao-recomendacoes-para-ouso-de-corretivos-e-fertilizantes-em-minas-g/1109073.

Soares, R. J. S., Pinto, A. A., Camara, F. T. \& Santana, L. D. (2017). Produtividade de massa verde de milho transgênico em função do arranjo populacional na região do Cariri, CE. Interações, Campo Grande, MS, 18(2), 117 - 127. https://doi.org/10.20435/inter.v18i2.1444.

Soares, F. C., Peiter, M. X., Robaina, A. D., Vivan, G. A. \& Parizi, A. R. C. (2012). Resposta da cultura do milho a variabilidade hídrica em solos sob pivô central. Irriga, Botucatu, 17(2), 220 - 233. https://doi.org/10.15809/irriga.2012v17n2p220.

Uate, J. V., Pinho, R. G. V., Cancellier, L. L., Camilo, A. \& Júnior, L. A. Y. B. (2015). Épocas de semeadura e distribuição espacial de plantas na produção de milho. Revista Brasileira de Milho e Sorgo, 14(3), 346 - 357. http://dx.doi.org/10.18512/1980-6477/rbms.v14n3p346-357.

Vian, A. L., Amado, T. J. C., Cherubin, M. R., Simon, D. H., Damian, J. M. \& Bredemeier, C. (2016). Variabilidade espacial da produtividade de milho irrigado e sua correlação com variáveis explicativas de planta. Ciência Rural, 46(3), 464 - 471. https://doi.org/10.1590/0103-8478cr20150539.

Von Pinho, R. G., Gross, M. R., Steola, A. G. \& Mendes, M. C. (2008). Adubação nitrogenada, densidade e espaçamento de híbridos de milho em sistema plantio direto na região sudeste do Tocantins. Bragantia, 67(3), 733 - 739. https://doi.org/10.1590/S0006-87052008000300023. 